\title{
Physical function assessment of older adults with lower body fractures at 3 months post-discharge from hospital
}

This article was published in the following Dove Medical Press journal:

Therapeutics and Clinical Risk Management

\author{
Nurul 'Izzah Ibrahim' \\ Mohd Sharkawi Ahmad' \\ Mohamed S Zulfarinal \\ Sharifah Nurul Aqilah Sayed \\ Mohd Zaris ${ }^{2}$ \\ Zainal Abidin Nor Azlin ${ }^{3}$ \\ Isa Naina Mohamed' \\ Norazlina Mohamed' \\ Sabarul Afian Mokhtar ${ }^{2}$ \\ Ahmad Nazrun Shuid' \\ 'Department of Pharmacology, Faculty \\ of Medicine, Universiti Kebangsaan \\ Malaysia Medical Centre, Kuala \\ Lumpur, Malaysia; ${ }^{2}$ Department of \\ Orthopedics and Traumatology, \\ Faculty of Medicine, Universiti \\ Kebangsaan Malaysia Medical Centre, \\ Kuala Lumpur, Malaysia; ${ }^{3}$ Department \\ of Orthopedics \& Traumatology, \\ Hospital Kuala Lumpur, Kuala Lumpur, \\ Malaysia
}

Correspondence: Ahmad Nazrun Shuid Department of Pharmacology, Faculty of Medicine, Universiti Kebangsaan Malaysia Medical Centre, Jalan Yaacob Latif, Bandar Tun Razak, 56000 Batu 9 Cheras, Kuala Lumpur, Malaysia

Tel +60 391459576

Email anazrun@yahoo.com
Background and purpose: Physical function assessment can be performed to assess functional mobility among older adults, especially after a traumatic incident such as lower body fracture (LBF). The objective of this study was to evaluate physical function of older patients with LBF after 3 months of discharge from the hospital.

Patients and methods: A total of 89 patients were followed up at the discharge phase. Four independent variables were tested: age, sex, type of fracture, and use of a walking aid before fracture. Mobility and strength were assessed with the Timed Up and Go (TUG) test and handgrip strength (HGS) test, respectively.

Results: The majority of the patients were $\geq 65$ years old $(64 \%)$, female $(61.8 \%)$, of Chinese ethnicity $(50.6 \%)$, and had a hip fracture $(51.7 \%)$. The mean time for TUG test was 26.11 seconds, while mean HGS was $19.02 \mathrm{~kg}$. We found significant differences in TUG test scores with respect to all independent variables tested: age $(P=0.026)$, sex $(P=0.011)$, fracture type $(P<0.001)$, and use of a walking aid before fracture $(P=0.004)$. Significant differences were also detected in HGS test scores with respect to all independent variables tested: age $(P<0.001)$, sex $(P<0.001)$, fracture type $(P<0.001)$, and use of a walking aid before fracture $(P=0.035)$.

Conclusion: Increasing age, female sex, having a hip fracture, and use of a walking aid before fracture predicted reduction in the physical function and strength among older adults with LBF. Keywords: lower body fracture, Timed Up and Go test, handgrip strength test, rehabilitation

\section{Introduction}

The proportion of older adults is increasing in most countries. In Malaysia, the percentage of old-age people ( $>65$ years old) is expected to rise from $5 \%(2010)$ to $14.5 \%$ (2040). In 2016, the total fertility rate was reported as below the replacement level (1.9 babies born per woman throughout her reproductive life). ${ }^{1}$ This indicates that the population continues to grow older rapidly as fertility rates have fallen to very low levels and people tend to live longer. ${ }^{2}$ However, living longer does not mean that they are living healthier. Noncommunicable diseases are the main health concern among the older population worldwide. Osteoporosis has become one of the most common noncommunicable diseases among the aging population. ${ }^{3}$ It is characterized by low bone mass and structural deterioration of bone tissue, leading to bone fragility and ultimately fracture. Osteoporosis leads to $\sim 9$ million fractures annually worldwide. ${ }^{4}$ Osteoporotic fractures may affect any part of the human skeleton except the skull. Parts such as the proximal femur (hip), distal forearm, lumbar vertebrae, and ribs are the most common sites of osteoporotic fractures. ${ }^{5}$ It has been estimated that $>40 \%$ of postmenopausal women and $\sim 25 \%-33 \%$ of men aged 75 years and 
above will eventually experience osteoporotic fractures., Among all the osteoporotic fractures, hip fracture has received the most attention. There were many reports on the personal burden of this fracture, especially in terms of limited mobility. ${ }^{7,8}$

Hip fracture is one of the lower body fractures, which can be defined as any fractures that occur at the lower body parts including pelvis, lumbar vertebrae, upper leg, lower leg, ankle, foot, and toe. ${ }^{9}$ A hip fracture is often caused by a fall which may be associated with poor postural control or reduced muscle strength in the lower extremities. ${ }^{10,11}$ Asymmetric vestibular function in the older adults may significantly contribute to falls and hip fracture. ${ }^{12}$

Physical function assessment is important for individual patients and the health care system. ${ }^{13,14}$ According to Jarnlo and Thorngren, hip fracture patients were associated with a lower mean speed at 2 years after the fracture compared to their control group. ${ }^{15}$ Additionally, it has been noted that at 12 months postfracture, $<50 \%$ of hip fracture patients return to pre-fracture physical function. ${ }^{16,17}$ There are many important predictors for return to baseline physical function such as cognitive status, surgical interventions, age, other comorbid conditions, and course following surgery. ${ }^{18-21}$

Timed Up and Go (TUG) test is a common method to assess functional mobility among older adults in geriatric clinics. The test measures speed during several functional movements, such as standing up, walking, turning, and sitting down. The test is convenient to be performed in clinical settings with limited training and equipment required. ${ }^{22}$ This test is an integral measure of gait speed and balance, together with fall risk, which are the major determinants of osteoporotic fractures in clinical settings. ${ }^{23,24}$ Apart from TUG test, handgrip strength (HGS) test is recommended for the measurement of muscle strength and considered the simplest method for assessment of muscle function in clinical settings. ${ }^{25}$ In addition to assessing the strength of the upper extremities, HGS test has co-relation with the measurement of lower body strength ${ }^{26}$ and this indicates that the strength of both upper and lower body parts can be evaluated. HGS measurement is a reliable, valid, and feasible screening tool for the measurement of strength in multiple population. ${ }^{27}$ Jamar dynamometer which is a commonly used tool for HGS test is considered as a device with excellent reliability and is easy to use and recommended by several societies such as the American Society of Hand Therapists and Brazilian Society of Hand Therapists. ${ }^{28}$ Muscle function measured by this test is related to muscle mass, which is a strong determinant of bone size, ${ }^{29}$ bone volumetric density, ${ }^{30}$ and associated bone strength. Thus, an individual with decreased muscle strength is at an increased risk of fracture.

Although hip fractures represent less than half of osteoporotic fractures in the older population, there were many studies which reported solely on hip fracture. Lower body fractures have been reported to represent about one-third of all types of bone fractures. ${ }^{31}$ Thus, in our study, we included all fractures of the lower body parts and sought to assess the physical function of the patients with lower body fracture at 3 months post-discharge using TUG and HGS tests. In addition, we aimed to determine the relationship between age, sex, type of fracture, and use of a walking aid before fracture and TUG and HGS test scores. The relationships between the variables chosen may generate useful reference for clinicians in treating the patients with lower body fracture during their rehabilitation. To the best of our knowledge, this is the first detailed study to evaluate the physical function of patients with lower body fracture after discharged from hospitals in Malaysia. Other than that, this study is important due to multiracial population in Malaysia, in which the results might be different from other similar studies. Therefore, the health care system would gain benefit in improving their planning and management of patients with lower limb fracture specifically for the population in Malaysia.

\section{Patients and methods Study design and patients}

This study was part of a vast project "Malaysia Bone Health and Osteoporosis Study" (MALBONES) which was conducted from February 2014 to February 2016. Patients admitted for lower body fractures to orthopedic wards in two hospitals in Klang Valley, Malaysia (Hospital Canselor Tuanku Muhriz [HCTM] and Hospital Kuala Lumpur [HKL]) were included based on the following inclusion criteria: 1) aged 50 and above, 2) Malaysian citizenship, and 3) any type of lower body fracture (hip, upper leg, knee, lower leg, ankle, and foot). Meanwhile, patients with psychiatric problems, Alzheimer's disease, dementia, or pathological fractures other than osteoporosis, cancer patients, patients living outside the Klang Valley, and patients with hearing and speech problems were excluded from this study. The bases for exclusion criteria were inability to follow instructions well, to avoid bias, and to reduce dropout rate during the follow-up visit. Data collection for this study was divided into three phases: the pre-fracture phase, ward admission phase, and 3 months post-discharge phase. However, physical function assessments could only be carried out during the postdischarge phase. The minimum sample size was determined 
by using Green formula, $\mathrm{N}=50+8(\mathrm{~m})$, where $\mathrm{N}$ represents "total participants of study" while m represents "independent variable". ${ }^{32}$ In our study, four independent variables (age, sex, types of fracture, and use of a walking aid before fracture) were chosen as they were frequently used in previous physical assessment studies. ${ }^{24,33,34}$ Thus, after inputting all the values in the formula, the minimum sample required was 82 participants. By considering 30\% dropout rate, the minimum sample size was calculated to be 107 participants. Written informed consent was obtained from all participants. The local research committee of Universiti Kebangsaan Malaysia and the Research Committee Kuala Lumpur Hospital (IRC-IIR/2014/011/156) had given approvals to conduct this study. This study was conducted under the guidance of the Declaration of Helsinki.

\section{Procedures}

All information related to demographic (sex, age, ethnicity, anatomy of fractured parts, fracture type) and clinical criteria (number of comorbidities, family history of osteoporosis, history of fracture) was collected while the patients were in the ward. Mobility status of the patients before and after fracture was also recorded. For assessing pre-fracture mobility status, patients were interviewed at the ward and required to report whether they have used walking aid or not before the fracture incident. The functional mobility assessment of the patients was performed with TUG test, which measures the patients' ability to stand up from a $44 \mathrm{~cm}$ high armless chair, walk $3 \mathrm{~m}$, turn, walk back, and sit down. ${ }^{22,35,36}$ The TUG test was carried out in postfracture patients who could walk with or without a walking aid. Patients with walking aid could use the walking aid during the test. Patients who were unable to stand on their own and need help to get up were considered unable to perform this test and were excluded. The time needed to perform the test was a TUG test score and recorded in the unit of seconds. ${ }^{37}$ Each patient had one trial prior to performing the test, and any sort of human assistance was not permitted.

As for HGS test, only the dominant hand was tested, which gave higher readings than the nondominant hand ${ }^{38}$ and because assessing both hands might take more time and energy of the patients and researcher. Patients who were unable to sit properly and perform this test according to the procedure were not allowed to participate. Jamar Plus hand dynamometer (S.I. Instruments, Hilton, SA, Australia) which was set at the second position was used for this test. The second position has been assumed to be the most reliable and consistent position and is the position advocated for routine use. ${ }^{25}$ During the test, the patient was asked to lean on a chair and sit up straight. Then, the patient was asked to hold the Jamar Plus hand dynamometer with the elbow at $90^{\circ}$ flexion. After the patient was ready with this position, he/she was required to grip as hard as possible and the first reading was recorded. The patient was then asked to perform this test twice, and the highest score was taken as the final score for handgrip strength, recorded in the unit of kilogram. Prior to the second test, the patient was allowed to rest for 1 minute. ${ }^{25,39-41}$

\section{Statistical analyses}

Results were analyzed using SPSS software (version 22). Descriptive analysis was used to determine the frequency and percentage of mobility status of the patients, as well as to determine the minimum, maximum, and mean values of TUG and HGS test scores. The Mann-Whitney $U$ test was conducted to determine significant difference between independent variables and the TUG test score, by means of median (IQR) value. The independent samples $t$-test was used to determine significant difference between independent variables and the HGS test score, which was expressed as mean $\pm \mathrm{SD}$. The level of significance was taken as $P<0.05$

\section{Results}

At the initial phase (pre-fracture and ward admission), a total of 129 patients were recruited. At the final phase (3 months post-discharge), a total of 89 patients were left for the 3 months follow-up visit. The demographic data of the patients are shown in Table 1 . Of the 40 patients who dropped out, 14 were dead, 11 withdrew from the study, and 15 could not be contacted (Table 2 ).

\section{Frequency and percentage of walking aid status}

During pre-fracture phase, 32 (24.8\%) patients used walking aids and 97 (75.2\%) did not use walking aids. However, after 3 months of discharge from the hospital, the number of patients who used walking aids increased to $67(75.3 \%)$, while the number of patients who did not use walking aids decreased to $22(24.7 \%)$.

\section{TUG and HGS test scores}

The TUG and HGS tests were performed on patients after 3 months of hospital discharge following admission for lower body fractures. The TUG test was performed according to the procedure for 57 patients who could walk on their own, while HGS test was performed for 82 patients who could 
Table I The characteristics of the patients who remained after follow-up in this study

\begin{tabular}{|c|c|}
\hline Characteristics & Post-discharge phase, $n=89, \mathrm{~N}(\%)$ \\
\hline \multicolumn{2}{|l|}{ Sex } \\
\hline Male & $34(38.2)$ \\
\hline Female & $55(61.8)$ \\
\hline Age $($ mean $\pm S D)$ & $69.62 \pm 10.68$ \\
\hline \multicolumn{2}{|l|}{ Age group (years) } \\
\hline $50-64$ & $32(36.0)$ \\
\hline$\geq 65$ & $57(64.0)$ \\
\hline \multicolumn{2}{|l|}{ Ethnicity/race } \\
\hline Malay & $33(37.1)$ \\
\hline Chinese & $45(50.6)$ \\
\hline Indian & $11(12.4)$ \\
\hline \multicolumn{2}{|l|}{ Number of comorbidities } \\
\hline $0-2$ & $62(69.7)$ \\
\hline$\geq 3$ & $27(30.3)$ \\
\hline \multirow{2}{*}{\multicolumn{2}{|c|}{$\begin{array}{l}\text { Family history of } \\
\text { osteoporosis }\end{array}$}} \\
\hline & 7 (7.9) \\
\hline No & $82(92.1)$ \\
\hline \multicolumn{2}{|l|}{ History of fracture } \\
\hline Yes & $20(22.5)$ \\
\hline No & $69(77.5)$ \\
\hline \multicolumn{2}{|l|}{ Anatomy of fracture parts } \\
\hline Hip and femur & $51(57.3)$ \\
\hline Knee and lower leg & $18(20.2)$ \\
\hline Ankle and foot & $20(22.5)$ \\
\hline \multicolumn{2}{|l|}{ Fracture type } \\
\hline Hip fracture & $46(5 । .7)$ \\
\hline Other than hip fracture & $43(48.3)$ \\
\hline
\end{tabular}

Note: Adapted from Ibrahim NI, Ahmad MS, Zulfarina MS, et al. Activities of daily living and determinant factors among older adult subjects with lower body fracture after discharge from hospital: a prospective study. Int J Environ Res Public Health. 2018;15(5):1002. Creative Commons license and disclaimer available from: http:// creativecommons.org/licenses/by/4.0/legalcode. ${ }^{91}$

perform the test according to the procedure. The mean scores of TUG and HGS tests were 26.11 seconds and $19.02 \mathrm{~kg}$, respectively. The minimum, maximum, and mean values of TUG and HGS test scores are shown in Table 3.

\section{Relation between TUG and HGS test scores and independent variables (age, sex, types of fracture, and use of a walking aid before fracture)}

The TUG test scores showed significant changes with respect to all independent variables: age $(P=0.026)$, sex $(P=0.011)$, types of fracture $(P<0.001)$, and use of a walking aid before fracture $(P=0.004)$. Older patients $(\geq 65)$ needed more time to complete this test with a median (IQR) value of 23.75 (22) seconds compared to middle-aged patients (50-64) with 18.50 (11) seconds. In terms of sex, female patients showed a higher TUG test score with a median (IQR) of 23.20 (19) seconds compared to male patients with 17.38 (11) seconds. In terms of types of fracture, hip fracture patients required more time to complete this test compared to patients with non-hip fracture with median (IQR) values of 30.43 (29) and 16.61 (5) seconds, respectively. In terms of the use of a walking aid before fracture, patients who used walking aid before fracture required more time to complete this test than the patients who did not use walking aid before fracture, with median (IQR) values of 45.53 (39) and 19.47 (12) seconds, respectively.

Significant changes were also found in the HGS test scores with respect to all the independent variables: age $(P<0.001)$, sex $(P<0.001)$, types of fracture $(P<0.001)$, and use of a walking aid before fracture $(P=0.035)$. Middle-aged category showed higher mean scores compared to older category with a mean score of $25.34 \pm 10.22$ and $15.18 \pm 7.11 \mathrm{~kg}$, respectively. In terms of sex, male had a higher mean score with $26.18 \pm 9.37 \mathrm{~kg}$, compared to female with a mean score of $14.20 \pm 6.47 \mathrm{~kg}$. Meanwhile, the mean score of HGS test for hip fracture patients was lower with $15.12 \pm 7.82 \mathrm{~kg}$, compared to patients with non-hip fracture with a mean score of $22.74 \pm 9.97 \mathrm{~kg}$. In terms of walking aid use before fracture, patients who used walking aid had a lower mean score with $14.92 \pm 7.41 \mathrm{~kg}$ compared to patients who did not use walking aid with a mean score of $20.26 \pm 10.03 \mathrm{~kg}$. Descriptive statistics according to independent variables and data of TUG test score, HGS test score, and the independent variables are tabulated in Table 4.

\section{Discussion}

In our study, more than half of the patients needed to use walking aid for mobility following lower body fracture incidents. Hip fracture, which was recorded with a higher number of cases compared to other lower body fractures, was associated with high usage of walking aids after discharge from the hospital. According to Nygard et al, most hip

Table 2 Frequency and percentage of patients who succeeded for follow-up and causes for dropouts in the study

\begin{tabular}{l|l|l}
\hline Follow-up status (3 months after discharge) & Frequency, $\mathbf{N}$ & Percentage (\%) \\
\hline Successful for follow-up visit & 89 & 69.0 \\
Died & 14 & 10.9 \\
Withdrawn from the study & 15 & 11.6 \\
Unable to contact & $1 \mathrm{I}$ & 8.5 \\
\hline
\end{tabular}

Note: This table was in reference to Ibrahim et al. ${ }^{91}$ 
Table 3 The minimum, maximum, and mean values of TUG and HGS test scores

\begin{tabular}{l|l|l}
\hline Score values & TUG test score, $\mathbf{n = 5 7}$ & HGS test score, $\mathbf{n = 8 2}$ \\
\hline Minimum & 9.0 seconds & $2.0 \mathrm{~kg}$ \\
Maximum & 73.0 seconds & $48.7 \mathrm{~kg}$ \\
Mean & 26.1 seconds & $19.0 \mathrm{~kg}$ \\
\hline
\end{tabular}

Notes: Thirty-two patients were excluded from the TUG test as they were unable to stand on their own and needed help to get up. Seven patients were excluded from the HGS test as they were unable to sit properly and perform this test. Abbreviations: HGS, handgrip strength; TUG, Timed Up and Go.

fracture patients were discharged from their final inpatient setting with a wheeled frame. Over time, the patients changed to non-wheeled walking aids and about $40 \%$ of the patients had not returned to their pre-fracture mobility status. ${ }^{42}$ In the current study, the percentage of patients who used walking aid increased from pre-fracture phase (24.8\%) to postfracture phase $(75.3 \%)$. This was parallel with the results of Laufer et al which showed that at pre-fracture phase, only 18 hip fracture patients needed to use walking aids. During the first phase ( 3 weeks postoperation) and second phase (3 months postoperation), all the 44 patients $(100 \%)$ needed to use walking aids. Eventually at the third phase of the study (2 years postoperation), 42 patients still needed to use walking aids. ${ }^{43}$ This may indicate that hip fracture patients had a high risk of not regaining the pre-fracture mobility status. This agrees with our study in which the percentage of patients who used walking aids was increased from about $25 \%$ before fracture to about $75 \%$ after fracture.

It is postulated that if fracture stability is maintained, fracture impaction achieved by the weight-bearing phase of locomotion and fixation devices with sliding capabilities may enhance bone healing process ${ }^{44}$ Thus, regardless of full or slight application of burden on lower body parts, early ambulation that involves the use of walking aids seems to voluntarily limit loading on the injured limb. ${ }^{45}$ In older patients, slight application of burden on lower body parts may prevent medical complications that could inhibit healing process. ${ }^{46,47}$ The increased percentage of walking aid use after fracture in our study may be useful to promote fracture healing. In addition, physicians and physiotherapists should advise older patients to perform physical activity regularly, even light walking, to speed up healing process. Several previous studies had revealed that regular physical activity has been associated with better outcomes in the post-hip fracture period. ${ }^{48,49}$

TUG is a simple and quick test, requiring no special equipment or training to assess the status of mobility and the risk of falling among the older adults. TUG test is suitable to assess less healthy older people with lower functioning, as well as to predict the ability to go outside alone safely. ${ }^{22,50}$ A study conducted by Podsiadlo and Richardson showed that health problems among the older adults had an impact on the general mobility status and the TUG test score in particular. In the study, the time taken to complete the TUG test was longer, between 10 and 240 seconds, among older people with various health problems such as vascular cataract, Parkinson's disease, rheumatoid arthritis, post-surgery following hip, and cerebral degeneration. Podsiadlo and Richardson categorized the TUG test scores into three main groups: $<10$ (normal), 10-20 (good mobility, can go out alone, and no walking aid required), and 20-30 (problem in mobility, cannot go out alone, and requires walking aid). ${ }^{22}$ Our present study reported that after 3 months of lower body

Table 4 Descriptive statistics according to independent variables and data of TUG test scores, HGS test scores, and the independent variables

\begin{tabular}{|c|c|c|c|c|c|c|}
\hline \multirow[t]{2}{*}{ Independent variables } & \multicolumn{3}{|c|}{ TUG test, $\mathrm{n}=57$} & \multicolumn{3}{|c|}{ HGS test, $n=82$} \\
\hline & $\mathbf{N}(\%)$ & $\begin{array}{l}\text { Median (IQR) } \\
\text { (seconds) }\end{array}$ & $P$-value & $\mathbf{N}(\%)$ & $\begin{array}{l}\text { Mean } \pm \text { SD } \\
(\mathbf{k g})\end{array}$ & $P$-value \\
\hline \multicolumn{7}{|l|}{ Age (years) } \\
\hline $50-64$ & $27(47.4)$ & I8.5 (II) & 0.026 & $31(37.4)$ & $25.3 \pm 10.2$ & $<0.001$ \\
\hline$\geq 65$ & $30(52.6)$ & $23.8(22)$ & & $51(62.2)$ & $15.2 \pm 7.1$ & \\
\hline \multicolumn{7}{|l|}{ Sex } \\
\hline Male & $28(49.1)$ & $17.4(1 \mathrm{I})$ & 0.011 & $33(40.2)$ & $26.2 \pm 9.4$ & $<0.001$ \\
\hline Female & $29(50.9)$ & $23.2(19)$ & & $49(59.8)$ & $14.2 \pm 6.5$ & \\
\hline \multicolumn{7}{|l|}{ Fracture type } \\
\hline Hip fracture & $26(45.6)$ & $30.4(29)$ & $<0.001$ & $40(48.8)$ & $|5| \pm 7.8$. & $<0.001$ \\
\hline Non-hip fracture & $31(54.4)$ & $16.6(5)$ & & $42(51.2)$ & $22.7 \pm 9.9$ & \\
\hline \multicolumn{7}{|c|}{ Use of a walking aid before fracture } \\
\hline Yes & $9(15.8)$ & $45.5(39)$ & 0.004 & $19(23.2)$ & $14.9 \pm 7.4$ & 0.035 \\
\hline No & $48(84.2)$ & $19.5(12)$ & & $63(76.8)$ & $20.3 \pm 10.0$ & \\
\hline
\end{tabular}

Abbreviations: HGS, handgrip strength; TUG, Timed Up and Go. 
fracture, the mean TUG test score was 26.11 seconds, which fell into the "problematic, should not be allowed to go outside alone, and requires walking aid" category.

A study conducted by Ibrahim et al on a large sample of 2,084 older patients in Malaysia had established TUG test normative data based on cognitive status, sex, and age. The results showed that patients without mild cognitive problems had a lower mean TUG test score of $<14.3$ seconds for male and female. Meanwhile, for male and female patients with mild cognitive problems, the TUG test scores were $<12.9$ and 13.1 seconds, respectively. ${ }^{51}$ In our study, the mean TUG test score for both sexes with lower body fracture was 26.11 seconds, which was even higher than patients with mild cognitive problems. The longer time taken to complete the TUG test in our study indicated that the lower body fracture had severely affected the mobility and physical functions.

Our results also showed that the time required to complete the TUG test was longer compared to a study conducted among 62 patients undergoing hemiarthroplasty for displaced femoral neck fractures, aged between 55 and 100 years. This Canadian study showed that after 3 months of hemiarthroplasty surgery, the mean TUG test score of the patients was 17.00 seconds. In addition, this study revealed that the optimal threshold for predicting the need for a walking aid at 2 years postoperation was 58 seconds at 4 days and 26 seconds at 3 weeks. ${ }^{52}$ However, this finding could not be directly compared to the results of our study, since in our study TUG test was performed at 3 months post-discharge and included all types of lower body fractures, whereas the Canadian study had focused on hip fracture alone.

When compared to another study by Zasadzka et al, our study showed a longer mean time to complete the TUG test. The study of Zasadzka et al, which was conducted in Poland among older patients with lower extremity osteoarthritis, reported that older patients aged 60-69 years had a mean TUG test score of 12.9 seconds, while those aged 70-79 years had a mean TUG test score of 19.4 seconds. ${ }^{53}$ A longer time to complete TUG test was expected in our study as fracture of lower extremities is more serious than osteoarthritis, which might result in much worse condition and mobility status.

Several previous studies showed that a low TUG test score was closely related to low bone mineral density (BMD), increased risks of falling, and increased risk of bone fractures among the older adults. ${ }^{24,54}$ According to Bischoff et al, normal mobility of older adults aged $65-85$ years could be indicated with a TUG test score of $<12$ seconds. As the mean TUG test score of our study was 26.11 seconds, this may indicate high risks of falling and refracture. ${ }^{55}$
Hence, these findings should be taken seriously by the community and health professionals in terms of the impacts of lower body fractures on physical and mobility functions of older patients, and precautionary actions should be taken to prevent bone refracture.

Our results showed an association of TUG test score with all independent variables tested: age, sex, types of fracture, and use of walking aid before fracture. Based on several previous studies among the older adults, increasing age was the main factor contributing to lower TUG test score. ${ }^{56-58}$ In the older adults, muscular weakness, poor balance, and neuromuscular abnormalities decrease mobility and lower the performance in daily activities and physical function. ${ }^{59,60}$

In our study, female sex showed significantly lower TUG test score compared to male, coinciding with the study of Thompson and Medley which reported that women were slower than men in TUG test $(P<0.01)$ and the difference was much greater when using walking aid $(P<0.0001)$. However, the participants involved were not fracture patients, but community-dwelling older adults using or not using walking aid. ${ }^{61}$ In addition, there were also other studies conducted among aging adults which showed that female sex had a lower TUG test score than men. ${ }^{24,51,62}$ However, there was no strong consensus on sex-related findings on TUG test scores, as several other studies found no association between TUG test score and sex. ${ }^{54,63}$

In terms of the types of fracture, our study showed that hip fracture patients had a significantly lower TUG test score than patients with other lower body fractures. Previous studies on hip fracture patients also coincided with our results, revealing that the types of fracture may influence health outcomes. ${ }^{42,57,58}$ However, a study conducted by Kronborg et al on hip fracture patients aged 65 years and above did not find any significant difference between the TUG test score and types of fracture. ${ }^{64}$ Nevertheless, the findings by Kronborg et al must be carefully interpreted as the sample size was small (only 36 patients).

Our study demonstrated the association between the use of walking aid before fracture and the TUG test score. Lusardi et al suggested that the use of walking aid was associated with significantly slower TUG test scores among community-dwelling people aged 66-101 years. ${ }^{33}$ This was also in accordance with the study of Cook et al which correlated slower performance in the TUG test with the use of walking aids pre- and postfracture. ${ }^{65}$

HGS test is a recommended assessment technique for the measurement of muscle strength and is the simplest method for clinical assessment of muscle function. As an assessment 
measure, HGS test has been shown to have predictive validity and low values are related with falls, ${ }^{66}$ disability, impaired health-related quality of life, ${ }^{67}$ and increased mortality. ${ }^{68,69}$ Grip strength can be measured quantitatively using a hand dynamometer. In our study, we used Jamar hand dynamometer which was set at the most reliable position (second position) for all participants. Handle positions 1 and 5 have been found to be significantly less reliable than the other positions, but for people with very small hands, position 1 may be appropriate..$^{25}$

Several previous studies conducted among older adults revealed that lower HGS test scores were closely related to the decline in physical, social, and daily activities. In addition, low HGS test scores were also associated with low $\mathrm{BMD}$, higher risk of falling, osteoporosis, and fragile bone fractures. ${ }^{70-75}$ The mean HGS test score found in our study at 3 months post-discharge was $19.02 \mathrm{~kg}$, which was higher than a score of $14.50 \mathrm{~kg}$ reported by Taha and Sulaiman. The latter study was conducted among healthy older men and women aged 60-83 years in Malaysia with a limited sample size of only 30 subjects. ${ }^{76}$ Lam et al attempted to establish a normative data for HGS test among Malaysians aged $>60$ years without neurological conditions. They reported a higher mean HGS test score compared to our HGS test mean score. The mean HGS test scores for both sexes in urban area were 24.4 and $21.8 \mathrm{~kg}$ for the right- and left-hand side, respectively. ${ }^{77}$ Our study only tested the HGS of the dominant hand of the participants with lower body fractures. This might contribute to the different mean HGS scores.

There were statistically significant differences in the HGS test scores for all the independent variables tested in our study (age, sex, fracture type, and use of a walking aid before fracture). The HGS test score of older age category was lower than middle age category, which coincided with several previous studies. This indicated that age was a determinant factor for HGS test scores. ${ }^{78-81}$ The aging process is associated with deteriorations in functional system (deficits in balance and strength performance), neural system (loss of sensory/motor neurons), muscular system (particularly type II muscle fibers atrophy), and bones (eg, osteoporosis), which may contribute to reduction of HGS test score in older adults. ${ }^{82}$

In addition, our study was in line with several previous studies that showed sex as an important factor affecting the HGS test score. This was expected due to physiological variations, with female having significantly lower mean HGS test score compared to male. ${ }^{78,80,83}$ In general, male have consistently higher HGS test score compared to female throughout life, due to higher levels of androgenic hormones, greater muscle mass, ${ }^{84,85}$ and greater height and weight. ${ }^{78,86}$

In our study, the mean HGS test score for hip fracture patients was significantly lower than patients with other fracture types. This might be due to the fact that older population were prone to have fracture at low BMD-prone area such as the hip, proximal humerus, and vertebrae. ${ }^{87}$ According to Serdaroğlu Beyazal et al, HGS test score was significantly correlated with BMD, as postmenopausal women with osteoporosis had a lower HGS test score than postmenopausal women with normal BMD. ${ }^{88}$

According to previous studies, mobility problems in older adults were closely associated with low HGS test score. The presence of frailty and other age-related conditions such as sarcopenia and osteoporosis may worsen mobility and strength difficulties in older adults and contribute to low HGS test score..$^{11,89,90}$ This was in line with our study as the dependency on walking aids before fracture was significantly associated with low HGS test score measured at 3 months post-discharge.

This study has several limitations. First, the follow-up period of 3 months for TUG and HGS assessments seems to be quite short. Ideally, the patients should be followed up at longer periods to have better assessments for reflections of mobility and strength after lower body fracture. In addition, the data on the walking aid status should be collected timely, as this may reflect the patients' condition after the fracture. The second limitation is regarding the tests used for statistical analysis. A multivariant regression is required to control the other potential confounding factors. However, due to the dropouts and the strict procedure of both tests, we managed to obtain a limited sample size. The limited sample size did not fit with the multivariate approach which may affect the result interpretation of the constructed model. Alternatively, we performed nonparametric (Mann-Whitney $U$ test) and parametric (independent samples $t$-test) tests to determine the significant differences. Preferably, a higher dropout rate for sample size calculation needs to be estimated to prevent this issue. For future studies, we will address these issues carefully.

\section{Conclusion}

This was the first study on TUG and HGS assessments of older patients with lower body fractures in Malaysia. Age, sex, types of fracture, and use of a walking aid before fracture could influence the physical function and strength of fracture patients. This could provide useful reference for the clinicians, researchers, and the community involved in the rehabilitation 
and treatment of older fracture patients in Malaysia and other developing countries with similar demographic profiles. Even though the outcomes can be predicted based on several previous research, this study was performed to confirm the outcome for the Malaysian population due to differences in demographic, socioeconomic, and lifestyle aspects, and thus to improve the strategy for rehabilitation among our population. In the future, this study might contribute to the implementation of patient-centered discharge planning (ie, individualized discharge plans) instead of the routine discharge care that is currently practiced in many hospitals.

\section{Acknowledgments}

The authors would like to thank the Ministry of Higher Education (MOHE) and the orthopedic ward staff of HCTM and HKL and the Pharmacology Department staff for their technical support. This research was funded by Universiti Kebangsaan Malaysia via Dana Impak Perdana (Premier Impact Grant DIP-2013-002).

\section{Disclosure}

The authors report no conflicts of interest in this work.

\section{References}

1. Kei HM. Population projection. Malaysia. 2017:2010-2040.

2. Bloom DE, Luca DL. The global demography of aging: facts, explanations, future. In: Piggott J. editor. Handbook of the Economics of Population Aging. Oxford: Elsevier; 2016:3-56.

3. Ingemarsson AH, Frändin K, Mellström D, Möller M. Walking ability and activity level after hip fracture in the elderly - a follow-up. J Rehabil Med. 2003;35(2):76-83.

4. Johnell O, Kanis JA. An estimate of the worldwide prevalence and disability associated with osteoporotic fractures. Osteoporos Int. 2006; 17(12):1726-1733.

5. Klotzbuecher CM, Ross PD, Landsman PB, Abbott TA, Berger M. Patients with prior fractures have an increased risk of future fractures: a summary of the literature and statistical synthesis. J Bone Miner Res. 2000;15(4):721-739.

6. Dobbs MB, Buckwalter J, Saltzman C. Osteoporosis: the increasing role of the orthopaedist. Iowa Orthop J. 1999;19:43-52.

7. Jones G, Nguyen T, Sambrook PN, Kelly PJ, Gilbert C, Eisman JA. Symptomatic fracture incidence in elderly men and women: the Dubbo Osteoporosis Epidemiology Study (DOES). Osteoporos Int. 1994;4(5): 277-282.

8. Vijayakumar R, Büsselberg D. Osteoporosis: an under-recognized public health problem. Glob J Health Sci. 2016;2016(1):2.

9. Clift B, Tibrewal S. Fractures of the lower limb (includes foot). 2018. Available from: https://www.researchgate.net/publication/254506497_ Fractures_of_the_Lower_Limb_includes_foot. Accessed June 18, 2018.

10. Obrant K. Orthopedic treatment of hip fracture. Bone. 1996;18(3): S145-S148.

11. Jarnlo GB, Thorngren KG. Background factors to hip fractures. Clin Orthop Relat Res. 1993;287:41-49.

12. Kristinsdottir EK, Jarnlo GB, Magnusson M. Asymmetric vestibular function in the elderly might be a significant contributor to hip fractures. Scand J Rehabil Med. 2000;32(2):56-60.
13. Gorman E, Chudyk AM, Hoppmann CA, et al. Exploring older adults' patterns and perceptions of exercise after hip fracture. Physiother Can. 2013;65(1):86-93.

14. Grigoryan KV, Javedan H, Rudolph JL. Orthogeriatric care models and outcomes in hip fracture patients: a systematic review and meta-analysis. J Orthop Trauma. 2014;28(3):e49-e55.

15. Jarnlo GB, Thorngren KG. Standing balance in hip fracture patients. 20 middle-aged patients compared with 20 healthy subjects. Acta Orthop Scand. 1991;62(5):427-434.

16. Magaziner J, Fredman L, Hawkes W, et al. Changes in functional status attributable to hip fracture: a comparison of hip fracture patients to community-dwelling aged. Am J Epidemiol. 2003;157(11):1023-1031.

17. Osnes EK, Lofthus CM, Meyer HE, et al. Consequences of hip fracture on activities of daily life and residential needs. Osteoporos Int. 2004; 15(7):567-574.

18. Ariza-Vega P, Jiménez-Moleón JJ, Kristensen MT. Non-weight-bearing status compromises the functional level up to $1 \mathrm{yr}$ after hip fracture surgery. Am J Phys Med Rehabil. 2014;93(8):641-648.

19. Beaupre LA, Jones CA, Johnston DW, Wilson DM, Majumdar SR. Recovery of function following a hip fracture in geriatric ambulatory persons living in nursing homes: prospective cohort study. $J$ Am Geriatr Soc. 2012;60(7):1268-1273.

20. Ortiz-Alonso FJ, Vidán-Astiz M, Alonso-Armesto M, et al. The pattern of recovery of ambulation after hip fracture differs with age in elderly patients. J Gerontol A Biol Sci Med Sci. 2012;67(6):690-697.

21. Taraldsen K, Sletvold O, Thingstad P, et al. Physical behavior and function early after hip fracture surgery in patients receiving comprehensive geriatric care or orthopedic care - a randomized controlled trial. J Gerontol A Biol Sci Med Sci. 2014;69(3):338-345.

22. Podsiadlo D, Richardson S. The timed "Up \& Go": a test of basic functional mobility for frail elderly persons. J Am Geriatr Soc. 1991; 39(2):142-148.

23. Fillit H, Rockwood K, Woodhouse K. Brocklehurst's Textbook of Geriatrics and Clinical Gerontology. 7th ed. Philadelphia: Saunders Elsevier; 2010.

24. Mousa SM, Rasheedy D, El-Sorady KE, Mortagy AK. Beyond mobility assessment: timed up and go test and its relationship to osteoporosis and fracture risk. J Clin Gerontol Geriatr. 2016;7(2):48-52.

25. Roberts HC, Denison HJ, Martin HJ, et al. A review of the measurement of grip strength in clinical and epidemiological studies: towards a standardised approach. Age Ageing. 2011;40(4):423-429.

26. Silventoinen K, Magnusson PK, Tynelius P, Kaprio J, Rasmussen F. Heritability of body size and muscle strength in young adulthood: a study of one million Swedish men. Genet Epidemiol. 2008;32(4): 341-349.

27. Cuesta-Vargas A, Hilgenkamp T. Reference values of grip strength measured with a Jamar dynamometer in 1526 adults with intellectual disabilities and compared to adults without intellectual disability. PLoS One. 2015;10(6): 0129585.

28. Matias Barbosa A. Confiabilidade e validade de um dispositivo de célula de carga para avaliação da força de preensão palmar [Reliability and validity of a load cell device for hand grip strength assessment]. Fisioter Pesqui. 2015;22:378-385. Portguese.

29. Heinonen A. Muscle cross-sectional area is associated with specific site of bone in prepubertal girls: a quantitative magnetic resonance imaging study. Bone. 2001;29(4):388-392.

30. van Langendonck L, Claessens AL, Lysens R, Koninckx PR, Beunen G. Association between bone, body composition and strength in premenarcheal girls and postmenopausal women. Ann Hum Biol. 2004;31(2): 228-244.

31. Kaye JA, Jick H. Epidemiology of lower limb fractures in general practice in the United Kingdom. Inj Prev. 2004;10(6):368-374.

32. Green SB. How many subjects does it take to do a regression analysis. Multivariate Behav Res. 1991;26(3):499-510.

33. Lusardi MM, Pellecchia GL, Schulman M. Functional performance in community living older adults. J Geriatr Phys Ther. 2003;26(3): 14-22. 
34. Steffen TM, Hacker TA, Mollinger L. Age- and gender-related test performance in community-dwelling elderly people: Six-Minute Walk Test, Berg Balance Scale, Timed Up \& Go Test, and gait speeds. Phys Ther. 2002;82(2):128-137.

35. Siggeirsdottir K, Aspelund T, Jonsson BY, et al. Effect of vertebral fractures on function, quality of life and hospitalisation the AGESReykjavik study. Age Ageing. 2012;41(3):351-357.

36. Greene BR, O’Donovan A, Romero-Ortuno R, Cogan L, Scanaill CN, Kenny RA. Quantitative falls risk assessment using the timed up and go test. IEEE Trans Biomed Eng. 2010;57(12):2918-2926.

37. Herman T, Giladi N, Hausdorff JM. Properties of the "timed up and go" test: more than meets the eye. Gerontology. 2011;57(3):203-210.

38. Malhotra R, Ang S, Allen JC, et al. Normative values of hand grip strength for elderly singaporeans aged 60 to 89 years: a cross-sectional study. J Am Med Dir Assoc. 2016;17(9):864.e1-7.

39. Ashton LM. Serial grip strength testing-its role in assessment of wrist and hand disability. Internet J Surg. 2003;5(2):1-7.

40. Rosengren BE, Ribom EL, Nilsson JÅ, et al. Inferior physical performance test results of 10,998 men in the MrOS Study is associated with high fracture risk. Age Ageing. 2012;41(3):339-344.

41. Trutschnigg B, Kilgour RD, Reinglas J, et al. Precision and reliability of strength (Jamar vs Biodex handgrip) and body composition (dual-energy X-ray absorptiometry vs bioimpedance analysis) measurements in advanced cancer patients. Appl Physiol Nutr Metab. 2008;33(6):1232-1239.

42. Nygard H, Matre K, Fevang JM. Evaluation of Timed Up and Go Test as a tool to measure postoperative function and prediction of one year walking ability for patients with hip fracture. Clin Rehabil. 2016;30(5):472-480.

43. Laufer Y, Lahav M, Lenger R, Sprecher E. Functional recovery following pertrochanteric hip fractures fixated with the Dynamic Hip Screw vs. the percutaneous compression plate. Scientific WorldJournal. 2005;5: 221-229.

44. Gotfried Y. Percutaneous compression plating for intertrochanteric hip fractures: treatment rationale. Orthopedics. 2002;25(6):647-652.

45. Koval KJ, Sala DA, Kummer FJ, Zuckerman JD. Postoperative weightbearing after a fracture of the femoral neck or an intertrochanteric fracture. J Bone Joint Surg Am. 1998;80(3):352-356.

46. Zuckerman JD, Zetterberg C, Kummer FJ, Frankel VH. Weight bearing following hip fractures in geriatric patients. Top Geriatr Rehabil. 1990;6(2):34-50.

47. Mincer AB. Assistive devices for the adult patient with orthopaedic dysfunction. Why physical therapists choose what they do. Orthop Nurs. 2007;26(4):226232-231233.

48. Fiatarone Singh MA, et al. Methodology and baseline characteristics for the Sarcopenia and Hip Fracture study: a 5 year prospective study. J Gerontol A Biol Sci Med Sci. 2009;64A(5):568-574.

49. Zidén L, Frändin K, Kreuter M. Home rehabilitation after hip fracture: a randomized controlled study on balance confidence, physical function and everyday activities. Clin Rehabil. 2008;22(12):1019-1033.

50. Schoene D, Wu SM, Mikolaizak AS, et al. Discriminative ability and predictive validity of the timed up and go test in identifying older people who fall: systematic review and meta-analysis. J Am Geriatr Soc. 2013;61(2):202-208.

51. Ibrahim A, Singh DKA, Shahar S. 'Timed Up and Go' test: age, gender and cognitive impairment stratified normative values of older adults. PLoS ONE. 2017;12(10):e0185641.

52. Laflamme GY, Rouleau DM, Leduc S, Roy L, Beaumont E. The Timed $\mathrm{Up}$ and Go test is an early predictor of functional outcome after hemiarthroplasty for femoral neck fracture. J Bone Joint Surg Am. 2012; 94(13):1175-1179.

53. Zasadzka E, Borowicz AM, Roszak M, Pawlaczyk M. Assessment of the risk of falling with the use of timed up and go test in the elderly with lower extremity osteoarthritis. Clin Interv Aging. 2015;10:1289-1298.

54. Khazzani H, Allali F, Bennani L, et al. The relationship between physical performance measures, bone mineral density, falls, and the risk of peripheral fracture: a cross-sectional analysis. BMC Public Health. 2009;9:297.
55. Bischoff HA, Stähelin HB, Monsch AU, et al. Identifying a cut-off point for normal mobility: a comparison of the timed "up and go" test in community-dwelling and institutionalised elderly women. Age Ageing. 2003;32(3):315-320.

56. Lusardi MM, Pellecchia GL, Schulman M. Functional performance in community living older adults. J Geriatr Phys Ther. 2003;26(3):14-22.

57. Kristensen MT, Foss NB, Kehlet H. Factors with independent influence on the "timed up and go" test in patients with hip fracture. Physiother Res Int. 2009;14(1):30-41.

58. Gomes GC, Teixeira-Salmela LF, Fonseca BE, et al. Age and education influence the performance of elderly women on the dual-task Timed Up and Go test. Arq Neuropsiquiatr. 2015;73(3):187-193.

59. Rantanen T, Guralnik JM, Sakari-Rantala R, et al. Disability, physical activity, and muscle strength in older women: the Women's Health and Aging Study. Arch Phys Med Rehabil. 1999;80(2):130-135.

60. Shimada H, Kim H, Yoshida H, et al. Factors associated with the timed up and go test score in elderly women. J Phys Ther Sci. 2010;22(3): 273-278.

61. Thompson M, Medley A. Performance of community dwelling elderly on the timed up and go test. Phys Occup Ther Geriatr. 1995;13(3):17-30.

62. Bohannon RW. Comfortable and maximum walking speed of adults aged 20-79 years: reference values and determinants. Age Ageing. 1997;26(1):15-19.

63. Sugimoto H, Demura S, Nagasawa Y. Age and gender-related differences in physical functions of the elderly following one-year regular exercise therapy. Health. 2014;06(08):792-801.

64. Kronborg L, Bandholm T, Palm H, Kehlet H, Kristensen MT. Feasibility of progressive strength training implemented in the acute ward after hip fracture surgery. PLoS One. 2014;9(4):e93332.

65. Shumway-Cook A, Brauer S, Woollacott M. Predicting the probability for falls in community-dwelling older adults using the Timed Up \& Go Test. Phys Ther. 2000;80(9):896-903.

66. Sayer AA, Syddall HE, Martin HJ, Dennison EM, Anderson FH, Cooper C. Falls, sarcopenia, and growth in early life: findings from the Hertfordshire cohort study. Am J Epidemiol. 2006;164(7):665-671.

67. Syddall HE, Martin HJ, Harwood RH, Cooper C, Aihie Sayer A. The SF-36: a simple, effective measure of mobility-disability for epidemiological studies. J Nutr Health Aging. 2009;13(1):57-62.

68. Cooper R, Kuh D, Hardy R. Mortality Review GroupFALCon and HALCyon Study Teams. Objectively measured physical capability levels and mortality: systematic review and meta-analysis. BMJ. 2010; 341:c4467

69. Gale CR, Martyn CN, Cooper C, Sayer AA. Grip strength, body composition, and mortality. Int J Epidemiol. 2007;36(1):228-235.

70. Wang X, Ma Y, Wang J, et al. Mobility and muscle strength together are more strongly correlated with falls in suburb-dwelling older Chinese. Sci Rep. 2016;6:25420.

71. Cheung CL, Tan KC, Bow CH, Soong CS, Loong CH, Kung AW. Low handgrip strength is a predictor of osteoporotic fractures: cross-sectional and prospective evidence from the Hong Kong Osteoporosis Study. Age. 2012;34(5):1239-1248.

72. Dixon WG, Lunt M, Pye SR, et al. Low grip strength is associated with bone mineral density and vertebral fracture in women. Rheumatology. 2005;44(5):642-646.

73. Kim SW, Lee HA, Cho EH. Low handgrip strength is associated with low bone mineral density and fragility fractures in postmenopausal healthy Korean women. J Korean Med Sci. 2012;27(7):744-747.

74. Szulc P, Feyt C, Chapurlat R. High risk of fall, poor physical function, and low grip strength in men with fracture-the STRAMBO study. J Cachexia Sarcopenia Muscle. 2016;7(3):299-311.

75. Taekema DG, Gussekloo J, Maier AB, Westendorp RG, de Craen AJ. Handgrip strength as a predictor of functional, psychological and social health. A prospective population-based study among the oldest old. Age Ageing. 2010;39(3):331-337.

76. Taha Z, Sulaiman R. A biomechanical study of grip and pinch strength among malaysian elderly population. Pertanika J Sci Technol. 2011;19(2): 293-305. 
77. Lam NW, Goh HT, Kamaruzzaman SB, Chin AV, Poi PJ, Tan MP. Normative data for hand grip strength and key pinch strength, stratified by age and gender for a multiethnic Asian population. Singapore Med J. 2016;57(10):578-584.

78. Kamarul T, Ahmad TS, Loh WY. Hand grip strength in the adult Malaysian population. J Orthop Surg (Hong Kong). 2006;14(2):172-177.

79. Abe T, Thiebaud RS, Loenneke JP. Age-related change in handgrip strength in men and women: is muscle quality a contributing factor? Age. 2016;38(1):28.

80. Adedoyin RA, Ogundapo FA, Mbada CE, et al. Reference values for handgrip strength among healthy adults in Nigeria. Hong Kong Physiother J. 2009;27(1):21-29.

81. Ong HL, Abdin E, Chua BY, et al. Hand-grip strength among older adults in Singapore: a comparison with international norms and associative factors. BMC Geriatr. 2017;17(1):176.

82. Granacher U, Gollhofer A, Hortobágyi T, Kressig RW, Muehlbauer T. The importance of trunk muscle strength for balance, functional performance, and fall prevention in seniors: a systematic review. Sports Med. 2013;43(7):627-641.

83. Keevil V, Mazzuin Razali R, Chin AV, Jameson K, Aihie Sayer A, Roberts H. Grip strength in a cohort of older medical inpatients in Malaysia: a pilot study to describe the range, determinants and association with length of hospital stay. Arch Gerontol Geriatr. 2013;56(1): 155-159.

84. Page ST, Amory JK, Bowman FD, et al. Exogenous testosterone (T) alone or with finasteride increases physical performance, grip strength, and lean body mass in older men with low serum T. J Clin Endocrinol Metab. 2005;90(3):1502-1510.
85. Gallup AC, White DD, Gallup GG. Handgrip strength predicts sexual behavior, body morphology, and aggression in male college students. Evol Hum Behav. 2007;28(6):423-429.

86. Kuh D, Hardy R, Butterworth S, et al. Developmental origins of midlife grip strength: findings from a birth cohort study. J Gerontol A Biol Sci Med Sci. 2006;61(7):702-706.

87. Kelsey JL, Samelson EJ. Variation in risk factors for fractures at different sites. Curr Osteoporos Rep. 2009;7(4):127-133.

88. Serdaroğlu Beyazal M, Devrimsel G, Küçükali Türkyılmaz A, Yıldırım M. The relationship of hand grip strength with bone mineral density and vitamin D in postmenopausal women. Türk Osteoporoz Dergisi. 2016;22(1):1-6.

89. Lino VT, Rodrigues NC, O’Dwyer G, Andrade MK, Mattos IE, Portela MC. Handgrip strength and factors associated in poor elderly assisted at a primary care unit in Rio de Janeiro, Brazil. PLoS One. 2016;11(11):e0166373.

90. Kannegieter LM. Mobility and handgrip strength but not aortic stiffness are associated with frailty in the elderly. J Gerontol Geriatr. 2016; 64(1):2-8.

91. Ibrahim NI, Ahmad MS, Zulfarina MS, et al. Activities of daily living and determinant factors among older adult subjects with lower body fracture after discharge from hospital: a prospective study. Int J Environ Res Public Health. 2018;15(5):1002.
Therapeutics and Clinical Risk Management

\section{Publish your work in this journal}

Therapeutics and Clinical Risk Management is an international, peerreviewed journal of clinical therapeutics and risk management, focusing on concise rapid reporting of clinical studies in all therapeutic areas outcomes, safety, and programs for the effective, safe, and sustained use of medicines. This journal is indexed on PubMed Central, CAS,

\section{Dovepress}

EMBase, Scopus and the Elsevier Bibliographic databases. The manuscript management system is completely online and includes a very quick and fair peer-review system, which is all easy to use. Visit http://www.dovepress.com/testimonials.php to read real quotes from published authors. 